\title{
Ed Wood brasileiro? Raffaele Rossi, Boca do Lixo e certa ideia de mau filme no Brasil
}

\author{
Laura Loguercio Cánepa' \\ https://orcid.org/0000-0003-3248-599X \\ Stephanie Dennison" \\ https://orcid.org/0000-0002-5699-8741 \\ I - University of Leeds. \\ Reino Unido. \\ II - Universidade Anhembi Morumbi. \\ São Paulo (SP). Brasil.
}

Resumo: Neste artigo, examinaremos alguns aspectos da redescoberta, por críticos e pesquisadores do cinema nacional, da obra do cineasta ítalobrasileiro Raffaele Rossi (1938-2007), dedicado à realização de filmes eróticos em São Paulo entre as décadas de 1970 e 1980. Buscaremos observar como esses pesquisadores e críticos, pautados, tanto pela má reputação do cinema paulista da Boca do Lixo quanto pelo culto contemporâneo ao chamado paracinema (SCONCE, 1995), também herdaram uma tradição de décadas dos estudos de cinema nacional que considera a precariedade como potência reveladora da singularidade do cinema brasileiro (SALLES GOMES, 1973; FERREIRA, 1986).

Palavras-chave: cinema brasileiro; Boca do Lixo; Raffaele Rossi; paracinema; filmes eróticos; precariedade.

Abstract: A Brazilian Ed Wood? Rafaelle Rossi, Boca do Lixo and the Idea of Bad Movies in Brazil - In this paper, we discuss the rediscovery of the Italian-Brazilian sexploitation filmmaker Raffaele Rossi (1938-2007) by Brazilian critics and researchers in the 2000s. We will observe how these researchers 
and critics, guided both by the bad reputation of the São Paulo cinema of "Boca do Lixo" [Mouth of Garbage] of the 1970s, and by the contemporary cult to the so-called paracinema (SCONCE, 1995), also inherited a tradition of decades of studies of the Brazilian cinema that consider precariousness as a power that reveals the uniqueness of Brazilian cinema (SALLES GOMES, 1973; FERREIRA, 1986).

Keywords: Brazilian cinema; Raffaele Rossi; paracinema; erotic movies; precariousness.

\section{Introdução}

No Brasil, o cineasta de origem italiana Raffaele Rossi (1938-2007) estará para sempre associado à pornografia hardcore que dominou a produção cinematográfica nacional na década de 1980, uma vez que seu filme Coisas Eróticas (1982) foi o primeiro filme brasileiro com cenas de sexo explícito a ser lançado comercialmente nos cinemas, abrindo as comportas para a rápida deterioração dos cinemas de rua nos centros de nossas cidades. Não é de admirar, portanto, que o conjunto dos trabalhos de Rossi (doze longas e vinte curtas-metragens) tenha sido desprezado pela crítica, e até mesmo, em parte, pelos fãs da produção cinematográfica associada à região da Boca do Lixo de São Paulo, principal centro de produção de filmes eróticos no Brasil nos anos 1970 e 1980, onde ele atuou na maior parte de sua carreira. A obra de Rossi pode ser localizada, quase sempre, entre o que havia de mais precário feito pelo cinema popular paulista, mas, devido principalmente a algumas exibições de seus filmes na TV a cabo, e também a pesquisas jornalísticas e acadêmicas recentes, as gerações mais jovens "descobriram" o diretor na segunda década dos anos 2000, e o interesse por ele despertado aponta para a possibilidade de se reavaliar a sua contribuição para a cultura cinematográfica nacional.

Neste trabalho, buscaremos examinar a redescoberta da obra de Rossi por críticos e pesquisadores brasileiros nos anos 2000, observando sua proximidade com o culto aos maus filmes denominado de paracinema (SCONCE, 1995) e com a celebração do diretor estadunidense Ed Wood, eleito nos anos 1980 como "o pior do mundo" e, desde então, cultuado no Brasil e no restante do planeta. Mas também desejamos demonstrar que a redescoberta de Rossi dialoga com uma tradição de décadas de estudos sobre os filmes 
brasileiros que vê na precariedade das obras uma potência reveladora da singularidade do cinema nacional, como se observa nos escritos de Paulo Emílio Salles Gomes (1973) e Jairo Ferreira (1986).

\section{Raffaele Rossi: de perdedor a "arrasa quarteirão"}

Raffaele Rossi enfrentou as mesmas dificuldades de quase todos os realizadores na instável indústria brasileira de cinema, mas, como ressalta Sanches, autor da dissertação de mestrado O homem que calou a Boca (2013), dedicada ao cineasta, essa experiência de instabilidade foi particularmente sensível para aqueles que, como Rossi, tiveram suas carreiras vinculadas ao local que se tornou o principal polo produtor de cinema popular do Brasil desde o final dos anos 1960 até meados dos 1980: a Boca do Lixo, em São Paulo.

Rossi não integrava o núcleo principal de realizadores da Boca. Na verdade, ele atuava em sua periferia e, eventualmente, aproveitava-se do fluxo de informação e de pessoal que por ali transitava (SANCHES, 2013, p. 13). Nascido de uma família de marceneiros da cidade de Sant'Arsenio, no sul da Itália, chegou ao Brasil aos 16 anos de idade, em 1954. Sem educação formal, mas com o hábito de frequentar as atividades da Igreja Católica, fez sua formação cultural em cineclubes e grupos de teatro católicos. Ao interessar-se pelo mundo artístico, passou a trabalhar como projecionista de cinema (SANCHES, 2013, p. 21), e, como relatam Godinho e Moura no livro-reportagem Coisas Eróticas - A história jamais contada da primeira vez do cinema brasileiro (2012, p. 17), também trabalhou em uma loja de equipamentos fotográficos. Então, em meados dos anos 1960, montou uma pequena produtora de filmes, a Companhia Cinematográfica Pindorama, junto com o amigo Inrineu Travallini (a.k.a. Toni Cardi), que atuava como corretor imobiliário em cidades como Piracicaba e Limeira, no interior de São Paulo.

Os métodos da Pindorama não eram sempre os mais honestos. Em entrevista ao pesquisador Gabriel Carneiro na revista eletrônica Zingu (CASTRO, 2011), o ator Ewerton de Castro revelou que, nos anos 1960, quando fez um filme com Rossi em Piracicaba, pôde testemunhar uma das muitas histórias pelas quais o realizador ganharia a fama de trambiqueiro. Segundo Castro, Rossi vendera para a cidade um documentário, dizendo aos comerciantes que mostraria suas lojas em troca de uma determinada quantia em dinheiro, mas "filmava a loja sem um metro de película na câmera. [...] Pegou dinheiro da cidade inteira e fugiu" (CASTRO, 2011). 
Foi como resultado de uma dessas trambicagens que Rossi realizou e estrelou seu primeiro longa-metragem de ficção, O Homem Lobo (Fig. 1), iniciado em 1966, mas lançado apenas em 1971. Como relata Sanches (2013, p. 14), em troca de hospedagem em um hospital em construção e de algum dinheiro para a realização do filme, Rossi deixou para os habitantes da cidade mineira de Alterosa (MG) seu primeiro documentário, intitulado A Cidade Sorriso (1966).

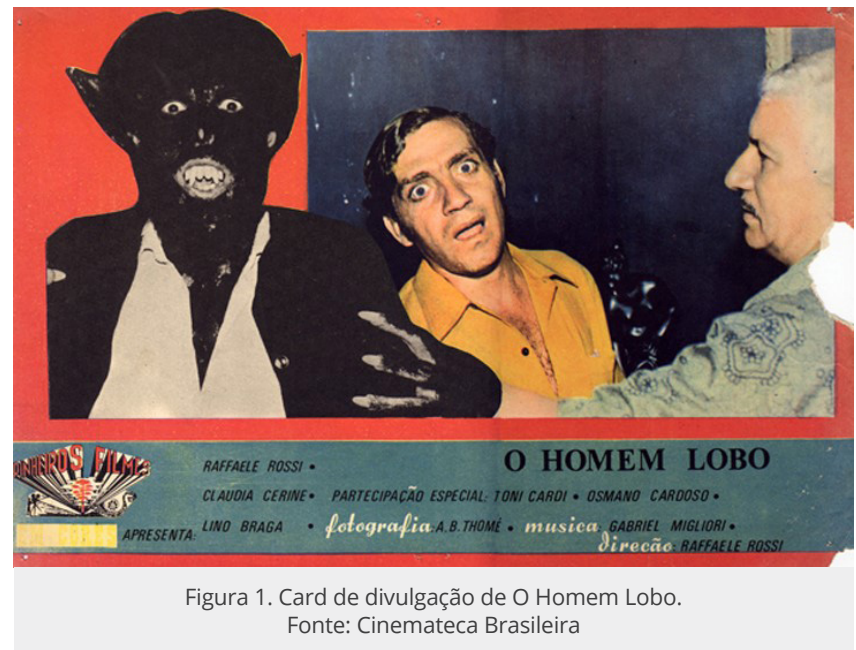

O Homem Lobo baseou-se no clássico da Universal Studios (The Wolf Man, George Waggner, 1941), mas contou uma história diferente: em uma cidade do interior, o professor Rogério (Lino Braga) e sua esposa Maria (Tereza Polidoro) amparam uma mulher que morre logo após parir um menino Roberto, logo adotado pelo casal. Anos depois, o filho está internado em uma escola distante devido à rejeição que sofre da mãe, mas o pai consegue se transferir para a mesma escola. $O$ adolescente (interpretado pelo próprio Rossi, então com quase 30 anos de idade) começa a manifestar sintomas de licantropia, deixando um rastro de mortes que acaba incriminando Rogério e também uma aluna da escola (Claudia Cerini). Por fim, o professor desiste de encobrir os crimes do filho e sai em sua caçada, junto com a polícia.

Em O Homem Lobo, Rossi combinou horror, melodrama e algumas doses de erotismo, seguindo o que acreditava ser a cartilha de seu colega de origem igualmente popular José Mojica Marins - que, poucos anos antes, lançara (e estrelara, no papel de Zé do Caixão) o longa-metragem À meia-noite levarei sua alma (1964), com enorme sucesso. Rossi, no entanto, não obteve o mesmo 
reconhecimento. Seu filme foi exibido em apenas um cinema na cidade de Capivari, no interior de SP, em maio de 1971, e depois em cidades do interior do estado (SANCHES, 2013, p. 28). Os anos seguintes também foram de extrema dificuldade. O western Pedro Canhoto, lançado em 1974 como Pedro Canhoto, o Vingador Erótico, foi rodado em Dourados (MG) e teve sua produção interrompida em 1972 por falta de dinheiro, sendo retomado por Cassiano Esteves, proprietário da distribuidora Marte Filmes, sediada na Boca do Lixo. Esteves ensinaria a Rossi um dos segredos do sucesso das produtoras da Boca: o acréscimo de títulos apelativos, com sugestões sexuais, a todos os filmes lançados.

Rossi voltaria à direção, roteiro e montagem em 1974, com a história de roubo de joias A Gata Devassa (1974) e, no ano seguinte, faria Seduzidas pelo Demônio (Fig 2), lançado pela Marte Filmes, em 1976. Rodado com o propósito de aproveitar o sucesso de O Exorcista (William Friedkin, EUA, 1973), o filme foi uma espécie de mashup da história de O Homem Lobo com a de O Exorcista. Em seguida, Rossi criou sua nova produtora, a Panther's Cine Som, pela qual faria as comédias eróticas Pura Como Um Anjo... Será Virgem? (1976) e Roberta, A Moderna Gueixa do Sexo (1978). Desta vez, com a ajuda de starlets do calibre de Helena Ramos no papel de Roberta (Fig 3), Rossi conseguiria angariar dois sucessos nas bilheterias, ainda que continuasse praticamente ignorado por seus colegas da Boca do Lixo.
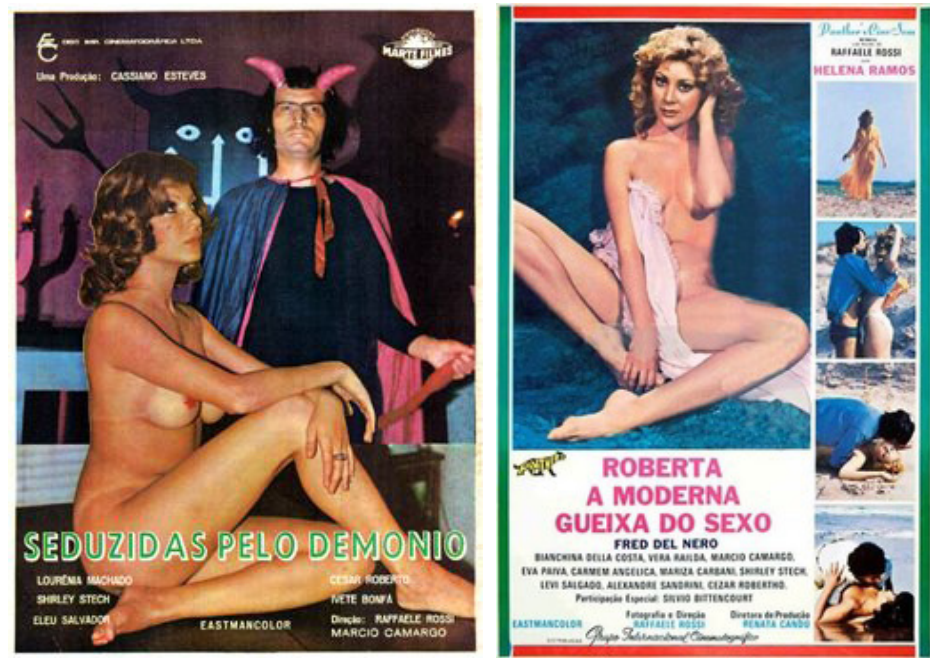

Figuras 2 e 3. Cartazes dos filmes Seduzidas pelo Demônio e Roberta - A moderna gueixa do sexo. Fonte: Cinemateca Brasileira 
Eventualmente também surgiam projetos como o musical João de Barro (1978), estrelado pelo cantor Ivan Carlos, ou Uma Cama Para Sete Noivas, co-dirigido com José Vedovato. Em 1981, Rossi também aproveitaria a onda das casas de massagem ${ }^{2}$ como cenário para o drama erótico $A$ Casa de Irene (1981). Em seguida, porém, sua sorte começaria a mudar. Ainda em 1981, Rossi lançaria o longa-metragem Boneca Cobiçada, estrelado por Aldine Müller, com uma cena muito discreta de penetração protagonizada pela atriz Vania Bonier, o que garantiu sucesso razoável de bilheteria para a fita ${ }^{3}$. Naquele momento, o Departamento de Censura Federal vinha sendo pressionado por produtores e distribuidores estrangeiros, que tentavam a liberação de filmes de sexo explícito nos cinemas do Brasil, o que criou uma "indústria de mandados de segurança" (GAMO, 2006, p. 26) que buscava assegurar a exibição de filmes proibidos. Desde o final da década anterior, Rossi já percebia que havia uma espécie de "corrida do ouro" em direção à exposição cada vez mais explícita de relações sexuais nas telas brasileiras, e, como mostram Godinho e Moura (2012, p. 05-07), parecia ver nesse filão uma possibilidade de redenção depois de uma vida de grandes dificuldades como produtor.

De fato, o começo dos anos 1980 foi um momento em que diversos filmes brasileiros começaram a testar os limites da pornografia, apresentando cenas de nu frontal masculino e feminino, com cenas de sexo simuladas cada vez mais ousadas, como havia sido o caso de Boneca Cobiçada. Finalmente, em 07 de julho de 1982 (dois dias após a trágica derrota do Brasil para a Itália na Copa do Mundo de Futebol) Rossi encontraria uma janela de oportunidade para lançar, no Cine Windsor, em São Paulo, o primeiro filme brasileiro com cenas de sexo explícito (NASCIMENTO, 2015, p. 144). O filme, dividido em três episódios, era Coisas Eróticas, codirigido por Rossi e Laerte Callichio. Como relatam Dennison e Shaw (2007, p. 100), esse filme foi resultado da aprovação, em 1981, da liberação de algumas salas para a exibição de material explícito (em filmes como A Força dos Sentidos, de Nagisa Oshima, 1978; e Caligula, de Tinto Bras, 1980). Coisas Eróticas (Fig. 4) solicitou um desses certificados, mas surpreendentemente conseguiu o certificado de liberação geral, sendo lançado com estardalhaço nos cinemas do Brasil, e alcançando um público oficial de mais de quatro milhões de espectadores em poucos

2 Identificação comum de casas de prostituição no Brasil, nos anos 1980.

3 Cerca de quinhentos e cinquenta mil espectadores. Fonte: ANCINE Tabela "Filmes brasileiros com mais de 500 mil espectadores". Disponível em: <https://oca.ancine.gov.br/cinema>. Acesso em: 20 mai. 2021. 
meses ${ }^{4}$. Na sequência de Coisas Eróticas, Rossi lançaria Coisas Eróticas // (1982) (Fig. 5), e faria ainda mais dois filmes de sexo explícito5, somando mais dois milhões de espectadores ${ }^{6}$.

O sucesso de Coisas Eróticas caiu como uma bomba no sistema da Boca: em 1983, dos 61 filmes produzidos em São Paulo, cerca da metade era de sexo explícito; até o final da década de 1980, cerca de quinhentos filmes pornográficos hard core seriam produzidos no Brasil, disputando espaço nos cinemas dos centros das cidades com filmes do mesmo gênero importados dos EUA e Europa. No entanto, esse domínio do mercado de filmes pelo cinema nacional, ainda que intenso, era indiscutivelmente destrutivo em vários níveis, e teve duração curta: no final da década de 1980, a produção de filmes na Boca do Lixo havia cessado (DENNISON; SHAW, 2007, p. 100). A crise econômica, a inflação e a competição com as produções em vídeo vindas dos EUA fizeram com que mesmo a produção de filmes pornográficos extremanente baratos não fosse mais viável.
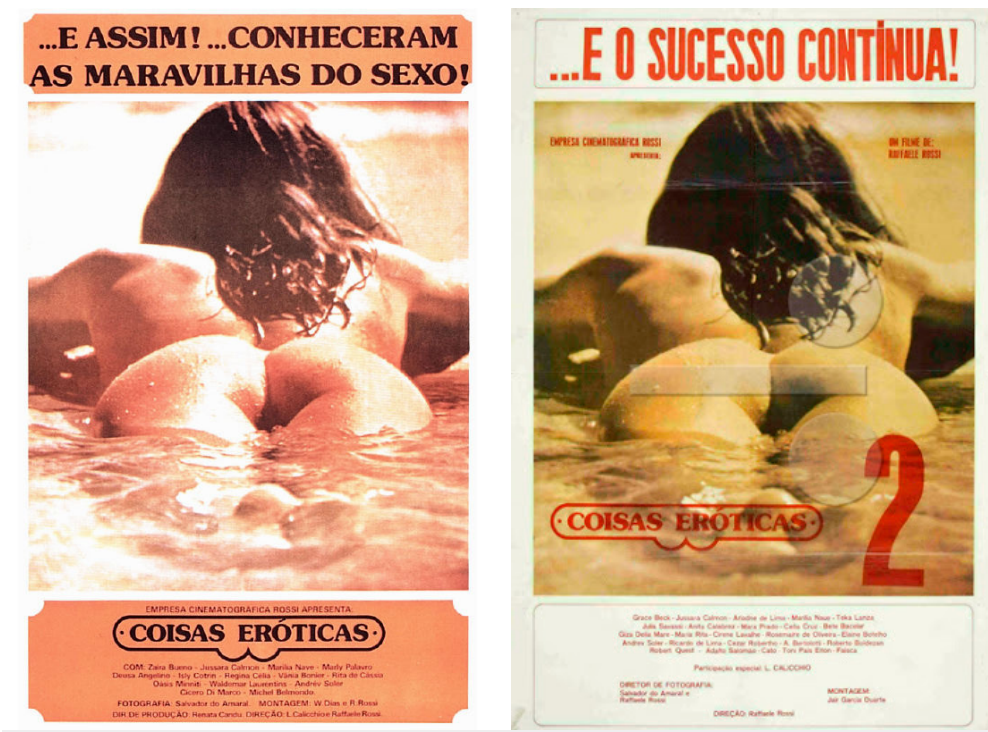

Figuras 4 e 5. Cartazes dos filmes Coisas Eróticas e Coisas Eróticas 2. Fonte: Cinemateca Brasileira

\footnotetext{
4 O filme teve um público oficial de 4.729.484 espectadores, segundo dados da Agência Nacional de Cinema (Fonte: ANCINE, Tabela "Filmes brasileiros com mais de 500 mil espectadores". Disponível em: <https://oca.ancine.gov.br/cinema)>. Acesso em: 20 jan. 2021.

5 De todas as maneiras (1983) e Gemidos e Surrurros (1987).

6 Sobre as bilheterias, ver tabela ANCINE Tabela "Filmes brasileiros com mais de 500 mil espectadores". Disponível em: <https://oca.ancine.gov.br/cinema>. Acesso em: 20 jan. 2021.
} 
Foi esse processo que tornou Rossi figura incontornável para a história do cinema brasileiro. Afinal, ele, que havia sido por um logo tempo considerado uma figura menor na Boca do Lixo, conhecido por filmes de má qualidade e, em sua maioria, pouco rentáveis, e ainda por estratégias questionáveis de buscas de patrocínio para suas produções, de repente viu-se diante do maior sucesso do mercado nacional de cinema erótico. Para se ter uma dimensão do sucesso de Coisas Eróticas, filmes considerados extraordinariamente bem-sucedidos na Boca, como o longa em episódios Noite das Taras (1981), haviam atraído cerca de dois milhões de espectadores ${ }^{7}$. Ao mesmo tempo, o sucesso de Rossi acabaria por iniciar o rápido declínio daquele ciclo de produção, redundando na destruição de carreiras de diretores que, até 1982, tinham encontrado sucessos de público e crítica muito maiores que os de Rossi, como Jean Garrett e Cláudio Cunha, que em alguns momentos haviam conseguido até mesmo furar a bolha de rejeição crítica ao cinema de Boca (sobre isso, ver: FERREIRA, 1986; MONTEIRO, 2019). É essa trajetória ambígua de sucesso e declínio que faz com que a produção de Rossi seja observada, hoje, com interesse especial por alguns cinéfilos, críticos e pesquisadores brasileiros que desejam compreender o ciclo da Boca do Lixo, um dos mais populares da história do cinema nacional.

\section{Sobre a precariedade (e o lixo) no cinema brasileiro}

Como observa Randal Johnson (2007, p. 03), a situação do cinema é particularmente precária em relação às outras artes no Brasil. Para o autor, a falta de uma base industrial necessária à atividade cinematográfica e a competição com indústrias cinematográficas altamente organizadas e capitalizadas tornam problemática a própria sobrevivência do cinema brasileiro (JOHNSON, 2007, p. 3). Mas é justamente dessa precariedade que esse cinema se alimenta, ao longo de sua história, como saída criativa para compensar as dificuldades. Isso se revela em diferentes propostas estéticas que vão desde a chanchada até o mais radical cinema moderno, e pode ser percebido também em denominações que fazem referência direta à precariedade: chanchada, estética da fome, estética do lixo, cinema marginal, cinema da Boca do Lixo (ou apenas "da Boca"), pornochanchada.

Não por acaso, Ella Shoat e Robert Stam (2014, p. 310) celebram a criatividade do Cinema Novo no Brasil, referindo-se à primeira leva desses filmes

7 Filme erótico soft core em episódios da produtora DACAR, de David Cardoso. Oficialmente, teve 2.127.829 espectadores Fonte: ANCINE Tabela "Filmes brasileiros com mais de 500 mil espectadores". Disponível em: <https://oca.ancine.gov.br/cinema>.Acesso em: 20 jan. 2021. 
como "detritos tropicais", já que sua técnica preferida seria uma colagem agressiva de discursos, um devoramento antropofágico de variados estímulos culturais em toda a sua heterogeneidade. Desde a estética da fome do Cinema Novo até a estética do lixo tropicalista que a sucedeu, um senso agressivo de marginalidade, de sobreviver na escassez, de ser condenado a reciclar os materiais da cultura dominante, é um mote importante não apenas para a compreensão crítica, mas também como pauta que aciona os realizadores (DENNISON, 2019, p. 166). É claro que nem todos os setores da sociedade brasileira veem o relacionamento da nação com o lixo como algo culturalmente transformador. Em 1958, Nelson Rodrigues cunhou a expressão "complexo de vira-lata", que, curiosamente, também tem relação com a ideia de catar detritos. Esse complexo de inferioridade também pode ser lido como um tipo de falha na reprodução (ou cópia) de genes, já que diz respeito a cães sem raça definida (DENNISON, 2019, p. 166).

Toda essa discussão em torno de sobras e falhas de reprodução pode ser encontrada também na defesa dos cineastas brasileiros feita pelo super influente crítico paulista Paulo Emílio Salles Gomes (1916-1977), na famosa afirmação feita em 1973: “Não somos europeus nem americanos do norte, mas destituídos de cultura original, nada nos é estrangeiro, pois tudo o é. [...] O filme brasileiro participa do mecanismo e o altera através de nossa incompetência criativa em copiar" (SALLES GOMES, 2016, p. 58). Salles Gomes foi provavelmente o mais fervoroso promotor do cinema brasileiro, moldando a consciência cinematográfica nacional ao concentrar-se nos efeitos da condição subdesenvolvida do país (CONDE; DENNISON, 2019, p. xxxii). Entre os muitos herdeiros das ideias de Paulo Emílio, um crítico que nos interessa em particular é Jairo Ferreira (1945-2003), que cunhou o termo "cinema de invenção" (FERREIRA, 1986) para identificar uma parcela significativa do mais radical cinema experimental brasileiro dos anos 1960/70, com especial atenção a cineastas do chamado "cinema marginal" como Rogério Sganzerla, cujo filme de estreia, O Bandido da Luz Vermelha (1968), foi produzido na Boca e se transformou em grande sucesso comercial. Para Ferreira: “O negócio é fazer filmes péssimos. Um apanhado crítico da face oculta do cinema nacional. Filmes péssimos, mas necessários. Chegou a hora de massacrar a visão europeizante que impede o cinema nacional de ser como deve ser" (2016, p. 67). Para Ferreira, o cinema de invenção tratava "de filmar a partir da impossibilidade de filmar" (2016, p. 67), e, para isso, o crítico resgatava a frase de Sganzerla dita pelo ator Paulo Villaça nos primeiros minutos de O Bandido: "quando um cara não pode fazer nada, ele avacalha e se esculhamba”. 
É nesse encontro de afirmações-chave sobre o cinema brasileiro que parece possível encontrar um ponto comum entre parte essencial da tradição crítica do cinema brasileiro e a atenção recentemente conquistada pelo cinema da Boca do Lixo em geral - e por Rafaele Rossi, um de seus mais infames representantes, em particular. Se, hoje, há reconhecimento de bons filmes e bons cineastas saídos daquele sistema de produção, como se observa em trabalhos de diversos autores (PIEDADE, 2002; MONTEIRO, 2019), é também inquestionável o fato de que boa parte daquela produção carece de um padrão mínimo de qualidade, tendo sido realizada para aproveitar a cota de tela então garantida pelo governo com filmes feitos a toque de caixa (PINKERTON, 2020) ${ }^{8}$. Mas, principalmente a partir dos anos 1990, a discussão internacional em torno desse tipo de filme ao mesmo tempo precário e de apelo sensacionalista (ao qual muitas vezes se atribui o termo $\operatorname{trash}^{9}$ ) parece ter encontrado guarida na jovem cinefilia que surgia no Brasil na virada dos anos 2000, dando também aos maus filmes da Boca um lugar especial no discurso crítico sobre o cinema nacional.

Como descreve Mayka Castellano, o culto aos filmes trash observado nos últimos trinta anos pode ser compreendido como uma “ideologia subcultural da construção de um gosto diferente do apresentado pelo público mainstream [que] sustenta a existência dessa comunidade de fãs que celebra o 'inassistível' - desagradável ou inacessível para a maioria dos espectadores" (2010, p. 140). O termo entrou em uso comum a partir do final dos anos 1980 para indicar uma gama ampla de expressões artísticas ou de entretenimento capazes de estimular e atrair o público pelo mau gosto, pela abordagem de temas tidos como vulgares e pela frequente baixa qualidade técnica.

No Brasil, o termo começou a ser usado a partir do final da década de 1980, inicialmente ligado a fanzines feitos por fãs de algumas correntes do punk rock ou por colecionadores de filmes de horror e exploitation. Em 1990, quando surgiu na TV Band o programa Cine Trash (apresentando Zé do Caixão como comentador de filmes de horror estrangeiros), o termo ficou

8 Relato sobre o impacto dos filmes da Boca do Lixo para as pessoas interessadas em filmes que fogem às convenções do bom gosto pode ser encontrado em texto recente publicado pelo crítico e pesquisador Nick Pinkerton (2020): Fuk Fuk à Rua do Triunfo - On Cinema da Boca do Lixo, Bolsonaro, and the Cinemateca Brasileira.

9 Como descreve David La Guardia (2008, p. 13), o termo trash [lixo] faz referência a uma categoria bastante ampla e diversificada de fenômenos, que, além da definição literal, recebe vários outros significados metafóricos que, sobretudo no inglês americano, são frequentemente utilizados e facilmente compreendidos como algo que se atribui às classes baixas (como na expressão white trash, que evoca as míticas famílias endogâmicas que vivem em trailers no interior dos EUA). 
indelevelmente vinculado ao cinema de horror no imaginário do público brasileiro. No entanto, como veremos, ainda que José Mojica Marins tenha se transformado em um grande ídolo trash no Brasil, sua (justa) elevação ao panteão dos grandes artistas nacionais - inclusive por meio do trabaIho de jovens críticos saídos diretamente dos fanzines para a rede mundial de computadores e para o mundo acadêmico ${ }^{10}$ - deixaria o espaço aberto para o surgimento de novos personagens, como Raffaele Rossi.

\section{Um tesouro trash para chamar de nosso}

Mathjis e Sexton atribuem, em parte, o processo de popularização mundial do culto aos maus filmes a partir da década de 1990 ao trabalho de cineastas como Quentin Tarantino ou Robert Rodriguez ("com seu desejo contínuo de fazer filmes exploitation cada vez mais caros") e também à acessibilidade crescente a itens tidos como trash que eram muito mais difíceis de encontrar antes do surgimento da Internet (2011, p. 95). Para Mathjis e Sexton, esse processo demonstra que o status dos objetos culturais pode mudar ao longo do tempo, e que o "lixo" de ontem pode se transformar no "tesouro" de amanhã (2011, p. 95).

Nesse sentido, é curioso observar o modo como alguns filmes de Rossi passaram a ser tratados por críticos brasileiros a partir dos anos 2000, particularmente aqueles em que o cineasta experimentou com o gênero horror. $\mathrm{Na}$ revista eletrônica Boca do Inferno (surgida em 2001 e ainda ativa na Internet) o crítico Paulo Blob Teixeira, um dos mais antigos fanzineiros ligados ao universo do punk rock no Brasil, começa assim o texto sobre Seduzidas pelo Demônio, disponibilizado em VHS nos anos 1980, e depois exibido pela TV a cabo no Canal Brasil:

Esse é um filme sobre um cara possuído pelo tinhoso que sai por aí matando garotas seminuas. E conta com a participação especial do Padre Quevedo! Sim, você não leu errado, ele mesmo, ainda que em uma pequena cena. [...] O diretor é o já falecido italiano Raffaele Rossi, um dos muitos picaretas da Boca do Lixo, que depois realizaria, dividindo a direção com Laerte Calicchio, Coisas Eróticas (1981), o primeiro filme brasileiro com cenas de sexo explícito. Raffaele Rossi demonstra em Seduzidas pelo

10 Destaque-se, aqui, o trabalho de Lúcio Reis Piedade, criador do B Zine, um dos principais fanzines brasileiros da década de 1990. Em 2002, sua dissertação de mestrado em Multimeios A cultura do lixo: horror, sexo e exploração no cinema foi defendida no Instituto de Artes, Universidade Estadual de Campinas, tratando-se do primeiro trabalho acadêmico brasileiro voltado a esse fenômeno. 
Demônio uma inaptidão digna de um Ed Wood ou Bruno Mattei, transformando o que era para ser um filme de terror, em muitos momentos, em uma autêntica comédia involuntária. (TEIXEIRA, 2014)

O texto chama a atenção, entre outras coisas, ao comparar Rossi a dois dos principais nomes do cinema trash mundial: os diretores Ed Wood (EUA, 19241978) e Bruno Mattei (Itália, 1931-2007), ambos conhecidos pelo interesse por temas fantásticos e eróticos, mas também pela estratégia frequente de usar cenas de filmes de outros diretores para enxertar em seus próprios trabalhos e, assim, completar as metragens e compensar a falta de recursos para efeitos especiais, cenários e locações. Como observa Teixeira, é exatamente isso que Rossi faz em Seduzidas:

[...] o professor conta que ele e sua esposa estavam de férias viajando pelo sul do Brasil, andando de carruagem e usando roupas típicas da região, quando pegaram um atalho conhecido como Vale das Mortes ("Não se assuste, madame, passaremos apenas por alguns cadáveres", alerta um dos passageiros). Mostra-se então imagens de árvores com enforcados e braços e pernas mutilados. $\mathrm{Na}$ verdade essas cenas foram roubadas, sem um pingo de vergonha na cara, da produção alemã Die Schlangegrube und das Pendel (1967) de Harald Reinl [...] lançado por aqui em tempos remotos pela Phoenix Vídeo como O Passado Tenebroso. (TEIXEIRA, 2014)

A resenha é ilustrativa de uma série de aspectos relacionados à sensibilidade trash que, nos anos 1990, ganhou de Jeffrey Sconce, no artigo Trashing the Academy, o título de paracinema, "uma emergente subcultura cinematográfica articulada em torno dos filmes de pior reputação e mais insatisfatórios da história do cinema" (SCONCE, 1995, p. 372). Em 1995, o pesquisador descrevia esse culto aos maus filmes a partir do conteúdo de revistas especializadas e fanzines que cultuavam diretores como Ed Wood, Bruno Mattei, Larry Buchanan, entre outros. Pouco tempo depois, esses textos migraram para o ciberespaço, onde proliferaram e pautaram uma corrente de pensamento e produção cultural que ainda hoje é uma das mais influentes e ativas, inclusive no Brasil. Como descrevia Sconce em 1995, o paracinema era "menos um grupo distinto de filmes do que um protocolo de leitura específico, uma contraestética voltada a uma sensibilidade subcultural dedicada a todo tipo de detrito cultural" (SCONCE, 1995, p. 372).

O que nos interessa a respeito dos textos que discutem a obra de Rossi são exatamente os protocolos de leitura descritos por Sconce, claramente 
aplicados por críticos brasileiros. Para Sconce, o culto paracinéfilo estaria voltado à valorização do desvio estilístico e temático nascido através da "falha sistemática ou distorção do estilo cinematográfico convencional por autores que são avaliados mais como excêntricos do que como artistas, por trabalharem dentro de condições de produção empobrecidas e clandestinas típicas do cinema de exploração" (SCONCE, 1995, p. 385). Nesse sentido, as soluções formais inusitadas e os flagrantes de elementos profílmicos (aqueles disponíveis diante da câmera para a construção da diegese cinematográfica), lidos como excessos textuais, estariam na base dessa espectatorialidade. Para Sconce:

[...] enquanto a atenção acadêmica ao excesso muitas vezes coloca em primeiro-plano estratégias estéticas dentro do texto como um sistema formal fechado, a atenção paracinemática ao excesso (um excesso que muitas vezes se manifesta no fracasso de um filme em se conformar aos códigos de verossimilhança historicamente delimitados), chama a atenção para o texto como um documento sociológico e cultural e, assim, dissolve as fronteiras da diegese em domínios profílmicos e extratextuais. $(1995$, p. 387)

Se voltarmos ao texto de Teixeira, percebemos que, de fato, o crítico brasileiro pratica aquilo que Sconce descreve como a observação dos aspectos profílmicos como estratégias de compreensão e mesmo valorização do filme de Rossi: ele repara no absurdo dos diálogos; na desculpa esfarrapada para justificar o uso de trechos de outro filme; mostra domínio de uma cinefilia marginal e admiração por autores de terceira linha; refere-se a aspectos do contexto extrafílmico (como a participação do Padre Quevedo). E, se compararmos sua crítica a uma das únicas publicadas na época do lançamento de Seduzidas pelo Demônio, veremos as mesmas observações, porém indignadas, feitas por outro crítico brasileiro, Luciano Ramos:

Estamos numa sala que, mesmo lembrando uma garagem, parece ser um tribunal. A cena é ambientada nos dias de hoje, o que não impede o juiz e advogados de vestirem togas agora só vistas em algumas cerimônias de colação de grau. [...] O ridículo atinge o ápice quando o filme resolve se mostrar educativo e tenta uma explicação científica para a possessão demoníaca. Assim, convida o Padre Quevedo, que, desavisado, comparece em pessoa, ministrando uma aula de parapsicologia que funciona como castigo extra para quem ainda estiver no cinema. [...] Cenas [...] produzidas pelo argumentista, 
roteirista, diretor de fotografia, montador, editor, diretor e produtor Raffaelle Rossi justapõem-se a seqüências literalmente roubadas de um filme de horror europeu [...]. Como vemos, o cinema comercial brasileiro está, a todo momento, demonstrando que ainda não atingiu seu nível mais baixo, podendo sempre descer mais. (RAMOS, 1977)

Até o final da década de 1990, exceto por alguns fanzines de circulação restrita no Brasil, a versão de Ramos era a que circulava majoritariamente em torno de filmes brasileiros como os de Rossi. No entanto, a partir da popularização da Internet, a posição dos críticos fanzineiros encontrou maior circulação, e coincidiu com um momento em que a cultura trash se popularizava intensamente no país. Isso favoreceu a releitura positiva de muitos filmes brasileiros, realizando o desejo dos cinéfilos de viver aquilo que Mathjis e Sexton descrevem como a experiência de estar diante de "algo 'diferente' [que] nos conduz a estranhas formas de apreciação" (MATHJIS; SEXTON, 2011, p. 95).

Os apreciadores do cinema trash brasileiro foram capazes de devolver a Rossi um lugar significativo dentro do discurso crítico sobre o cinema nacional. Além dos já mencionados pesquisadores Ruy Martins Sanches, Denise Godinho, Hugo Moura, Paulo Blob Teixeira e Gabriel Carneiro, outros pesquisadores e jornalistas também se interessaram pela experiência e pelos filmes de Rossi. Por exemplo, o já mencionado livro Coisas Eróticas, de Godinho e Moura, foi lançado juntamente com o documentáro A Primeira Vez do Cinema Brasileiro (Hugo Moura, Denise Godinho e Bruno Graziano, 2012). Na ocasião do lançamento, o jornalista André Barcinski afirmaria sobre o evento: “Sábado, 7 de julho, uma multidão vai se reunir no Cine Windsor, em São Paulo, para um tributo a um filme horroroso". E continua: "Até o próprio Rafaelle Rossi — que morreu em 2007 - sabia que seu filme não prestava". Então, pergunta ele, por que homenagear um filme tão ruim? “Fácil: porque a importância de Coisas Eróticas não é estética, é sociológica. [...] O documentário [...] conta não só a saga da produção do filme, mas a história do cinema da Boca e da transição da pornochanchada para o sexo explícito" (BARCINSKI, 2012).

Essa perspectiva adotada por nomes influentes da crítica e da paracinefilia brasileira pode ser encontrada também em outras matérias jornalísticas, principalmente tratando de O Homem Lobo. No mesmo ano do texto de Barcinski, o pesquisador Matheus Trunk (2012) realizaria, para a revista eletrônica Vice Brasil, uma entrevista com Toni Cardi, ex-sócio de Rossi. 
Na reportagem, afirmava que o ator e produtor preparava uma autobiografia em que relataria também as aventuras de Rossi, com destaque para os problemas com a polícia na produção de filmes como O Homem Lobo. Trunk também deu a Rossi espaço relevante em seu blog pessoal (Violão, Sardinha e Pão), com diversas matérias dedicadas a curiosidades de bastidores, como a primeira participação cinematográfica da dupla caipira Chitãozinho e Xororó, também em O Homem Lobo (2011). Antes de Trunk e Barcinski, o jornalista Carlos Primati já prestava seu tributo a Rossi em texto sobre os pioneiros do horror brasileiro. Ao falar sobre as primeiras produções do gênero no Brasil, dizia que: "a despeito da falta de mérito artístico, o filme [O Homem Lobo] ao menos atesta a existência de outros cineastas além de Mojica atentos às possibilidades do horror" (PRIMATI, 2009).

Talvez um modo interessante de se entender a posição de Rossi na cinefilia brasileira seja mesmo compará-la, como faz Primati, à posição conquistada por José Mojica Marins, tanto em termos das trajetórias quanto do tipo de atenção crítica que ambos receberam nos anos 2000. Mojica foi um dos mais originais cineastas brasileiros. Nascido em 1936, em São Paulo, começou sua carreira aos 18 anos quando fundou uma escola de cinema e começou a realizar filmes por meio de um sistema de cotas para alunos e amigos. Em 1956, o jovem Raffaele Rossi também vivenciou algo semelhante - mas, como relata Sanches (2012, p. 21), o plano não deu certo, e ele acabou detido pelas autoridades por estelionato. Enquanto Mojica conseguiu realizar seu primeiro longa-metragem na década de 1950 (o faroeste $A$ Sina do Aventureiro, 1957), e pouco depois inauguraria o cinema de horror nacional em 1964 ao estrelar, produzir e dirigir o extraordinário sucesso À Meia Noite Levarei Sua Alma (1964), Rossi apenas começaria as atividades da Pindorama em 1967, lançando seu filme de lobisomem em 1971, sem qualquer repercussão, no momento em que Mojica já era uma estrela.

Ambos enfrentaram altos e baixos ao longo da década de 1970, período em que estiveram mais diretamente ligados à Boca do Lixo. Os anos 1980 seriam cruéis com Mojica, enquanto Rossi encontraria nessa época seu momento de glória. Como relatam Godinho e Moura, o lucro obtido com Coisas Eróticas transformou-o em celebridade, fazendo com que gastasse fortunas em uma vida de luxo que acabou durando pouco: com o dinheiro que finalmente sobrava, Rossi fundou, nos anos 1980, um clube de futsal - o Grêmio Recreativo Rossi. Com a diminuição do dinheiro e o fracasso do time, o final de sua vida foi melancólico e quase miserável. Como relata 
Sanches, “Rossi morreu do mal de Alzheimer no dia 5 de novembro de 2007, na única propriedade que Ihe restava [...]. Ao seu lado estavam sua primeira esposa Davina, de quem nunca se separou oficialmente e dois de seus filhos - Rafael e Eduardo, além do caseiro Benedito" (2012, p. 50).

Já Mojica incrementou continuamente sua respeitabilidade como principal representante do cinema de gênero no Brasil, voltando a dirigir filmes (com destaque para a superprodução Encarnação do Demônio, 2008) e a apresentar programas de televisão nos anos 2000 (como o talk show O Estranho Mundo de Zé do Caixão, que estreou em 2008, no Canal Brasil, e teve seis temporadas). Ele chegou a ser homenageado em desfiles de carnaval por escolas de samba como a Rosas de Ouro, em São Paulo, em 2014, e Unidos da Tijuca, do Rio de Janeiro, em 2011. Faleceu em fevereiro de 2020, cercado pelos filhos, recebendo homenagens de toda a imprensa nacional, com direito a ser velado no Museu da Imagem e do Som (MIS, em São Paulo) com transmissão ao vivo pela Rede Globo - destaque reservado a pouquíssimos artistas no Brasil.

De formas e em proporções diferentes, Mojica e Rossi tornaram-se figuras cultuadas pelas novas gerações de espectadores brasileiros. O culto em torno de Mojica é mais antigo e já é observado há muito tempo. Conforme descreve Mayka Castellano, se para o público brasileiro, Zé do Caixão foi um sujeito amedrontador e frequentador de programas de auditório, "para muitos fãs de trash, Mojica é o ídolo maior, espécie de guru, pioneiro na arte de transformar ideias absurdas e recursos escassos em material fantástico, capaz de enlouquecer espectadores e críticos" (2010, p.152). Conforme apontado por Castellano (2010, pp. 153-4), na década de 1990, enquanto Mojica enfrentava sérias dificuldades financeiras e certo ostracismo, sua obra se tornava mais conhecida no exterior - e Zé do Caixão começava a ganhar o mundo como Coffin Joe. O sucesso começou quando André Barcinski, um dos autores da biografia de Mojica Maldito (1998), apresentou uma cópia de À Meia Noite Levarei sua Alma a Mike Vraney, fundador da distribuidora Something Weird. Em 1993, Vraney decidiu lançar filmes do diretor no mercado norte-americano, com sucesso significativo entre colecionadores e fãs de cinema de horror. A partir daí, segundo Castellano, consolidou-se uma situação que surgia de forma incipiente desde a década de 1970: enquanto no Brasil o Zé do Caixão era tratado como uma espécie de figura anedótica, no exterior tornou-se objeto de culto cinéfilo (2010, pp. 153-4) - culto que, com o tempo, influenciou definitivamente a forma como Mojica seria visto no Brasil. Como revela Primati: 


\begin{abstract}
Para a crítica norte-americana, quando da descoberta de José Mojica Marins no mercado de home video, em 1993, o cinema do autor parecia ter a estranheza surrealista de Luis Buñuel, combinava a elegância fetichista do italiano Mario Bava com o estilo ofensivo de John Waters, e até ameaçava destronar o ultrajante Herschell Gordon Lewis como padrinho do gore. O nova-iorquino Joe Kane, respeitado crítico especializado em filmes de horror, elegeu Coffin Joe como "a maior descoberta do gênero na década de 90", em seu guia The Phantom of the Movies' Videoscope, lançado em 2000. [...] As notícias desse súbito - e, em parte, tardio - interesse dos americanos pela obra de Mojica repercutiram imediatamente no Brasil, causando espanto. [...]. A incredulidade se justificava, em parte, devido ao longo período de inatividade de Mojica como cineasta, que havia lançado seu último longa-metragem profissional mais de uma década antes (PRIMATI, 2007).
\end{abstract}

O mesmo tipo de reconhecimento relativo às qualidades cinematográficas nunca poderia ser oferecido a Rossi, claramente menos capaz de sublimar as precárias condições de trabalho com inventividade e capacidade de liderança de equipes. O interesse por sua obra começou bem mais tarde, na segunda década dos anos 2000, e teve menor alcance, sendo parte de um culto mais amplo dos filmes da Boca do Lixo. Assim, nem por um momento houve, da parte daqueles que se dedicaram a examinar a obra de Rossi, qualquer tentativa de reconhecer em seus filmes alguma qualidade artística. Os críticos e fãs parecem perceber que, se Mojica foi capaz de usar as circunstâncias para intensificar a experiência de seus filmes, Rossi deixou em suas obras apenas as marcas do improviso e da inépcia que afastam o espectador da experiência imersiva do filme, levando-o a explorar o universo profílmico como uma saída para suportar a falta de estilo, o oportunismo temático, a pobreza das ideias, e o desperdício do trabalho de boas atrizes e atores que eventualmente trabalharam com ele.

\title{
O que os piores filmes nos ensinam
}

Raffaele Rossi é hoje uma figura acolhida pelos conhecedores do cinema popular e erótico brasileiro, tendo sido objeto de investigações jornalísticas e acadêmicas. Considerando a raridade desse tipo de trabalho entre os estudos brasileiros de cinema, Rossi, sem dúvida, tem recebido atenção especial. Mas, apesar de alguns contemporâneos de Rossi estarem agora no panteão de grandes cineastas brasileiros, nenhum pesquisador parece querer elevá-lo a essa posição de artista talentoso. Pelo contrário, existe 
uma unanimidade sobre sua inaptidão como cineasta. Assim, a cinefilia brasileira acabou encontrando para Rossi uma analogia na figura lendária de Ed Wood ${ }^{11}$, epítome conhecido pelos cinéfilos devido ao sucesso do filme Ed Wood (Tim Burton, 1994), e mencionado em comparações com Rossi por autores como Sanches (2013, p. 52), Cánepa (2013, p. 190) e Teixeira (2014).

Acomodar Rossi na posição do "pior" dá a ele um lugar especial em reconhecimento ao caráter autoral de sua obra (já que, por diferentes razões, ele acumulava em si, com frequência, quase todas as principais funções criativas) enquanto, ao mesmo tempo, preserva o prestígio de outros cineastas do circuito do cinema de exploração brasileiro que hoje são considerados mais relevantes do ponto de vista da competência como criadores cinematográficos. Nesse sentido, é curioso comparar Rossi a Ed Wood: os dois conseguiram ocupar posições do cinema popular de exploração em seus principais gêneros (o horror e o pornográfico); começaram suas carreiras em condições terrivelmente amadoras, fazendo uso de recursos privados (seus e de incautos); estrelaram alguns de seus próprios filmes; tiveram suas carreiras recuperadas postumamente em função de seus problemas e limitações. Apesar disso, ironicamente, nosso pior cineasta ao menos conheceu dias de glória ainda em vida, diferentemente de Ed Wood.

Examinar a notável trajetória de Rossi nos permite entender vários aspectos sobre o modo de se fazer filmes e sobreviver de cinema no Brasil. 0 interesse pelos filmes de Rossi parece retomar, em certa medida, a famosa entrevista de Paulo Emílio Salles Gomes, na qual afirmou que "encontramos tanto de nós mesmos num filme ruim [...] que em última análise é muito mais estimulante ao espírito e à cultura prestar atenção a esses filmes do que continuar a consumir produtos importados que nos dão conforto intelectual e satisfação estética" (REICHEMBACH; MAZZINI; ARAUJO, 2012, p. 79). A ideia de mau filme, assim, central para a formação da crítica nacional, parece ter encontrado guarida também no culto paracinéfilo que ainda hoje pauta parte da cultura cinematográfica no Brasil.

Nesse contexto, Raffaele Rossi surge como uma espécie de anti-herói cuja redenção se dá pela própria incompetência — transformada, por seus novos admiradores, em qualidade reveladora do contexto de improviso e miséria no qual trabalhou. Nos filmes de Rossi, encontramos características que são recorrentes no cinema brasileiro: a emulação bastante livre de modelos importados, que pode ser percebida pela variedade dos gêneros a que Rossi 
recorreu, sempre de olho em sucessos internacionais; a extrema precariedade de muitas produções, visível nos cenários vazios e mal-iluminados que mais se parecem com galpões e garagens; a constante necessidade de novos começos, verificada nas várias empresas (mal) administradas em pouco mais de duas décadas de carreira; a instabilidade dada pelo esgotamento econômico de certos ciclos produtivos, como ocorreu com o ciclo da Boca do Lixo. Tudo isso, é claro, revelado com uma desfaçatez espantosa. Hoje, quando o cinema brasileiro se encontra em mais uma de suas crises, parece válido relembrar o caminho singular de Rossi, tão distante e ao mesmo tempo tão próximo do Brasil de 2021.

Laura Loguercio Cánepa é professora do Mestrado em Comunicação da Universidade Anhembi Morumbi. É doutora em Multimeios pelo IAR-Unicamp, mestre em Ciências da Comunicação pela ECA-USP e graduada em Jornalismo pela FABICO-URFGS. Foi coordenadora dos cursos de Realização Audiovisual da Unisinos - RS e Jornalismo da FIZO -SP.

Ilcanepa@anhembi.br

Stephanie Dennison é professora associada de Estudos Brasileiros e membro fundador do Centre for World Cinemas (Centro de Cinemas Mundiais) da Universidade de Leeds - Inglaterra. É autora de diversos trabalhos sobre cinema brasileiro, entre os quais Remapping Brazilian Film Culture in the Twenty-First Century (Routledge, 2019).

s.dennison@leeds.ac.uk

Contribuições de cada autor: Laura Loguercio Cánepa - análise formal do corpus, curadoria de dados, fundamentação teórica e conceituação, metodologia, escrita, revisão e edição, construção de figuras/pesquisa de imagens. Stephanie Dennison - supervisão de projeto de pesquisa, fundamentação teórica e conceituação, metodologia, escrita, revisão e edição. 


\section{Referências}

BARCINSKI, A.; FINOTTI, I. Maldito - A vida e o cinema de José Mojica Marins, o Zé do Caixão. São Paulo: Editora 34, 1998.

BARCINSKI, A. Tributo muito bom a um filme muito ruim. Andre Barcinski Blog Folha. 03 jul. 2012. Disponível em: <https://tinyurl.com/yyyoqb8h>. Acesso em: 2 dez. 2020.

CÁNEPA, L. L. Seduzidas pelo Demônio. In: ALMEIDA, C. (Org). O Cemitério Perdido dos Filmes B. 1. ed. Belo Horizonte: Estronho, 2013, p. 190.

CASTELLANO, M. 2010. Quero ser José Mojica: o circuito de produção trash independente". Revista Contracampo, Niterói, n. 21, ago. 2010, p. 145-159.

CASTRO, E. Entrevista concedida a Gabriel Carneiro. Revista Eletônica Zingu. 31 dez. 2011. Disponível em: <https://revistazingu.net/2011/12/31/entrevista-ewerton-de-castro/> Acesso em: 2 dez. 2020.

CONDE, M.; DENNISON, S. Introductory Essay. In: . (Eds). Paulo Emílio Salles Gomes: On Brazil and Global Cinema. University of Wales Press, 2019.

CRAIG, R. Ed Wood, Mad Genius: a critical study of the films. Carolina do Norte: McFarland \& Company, 2009.

DENNISON, S. Sex and the Generals: Reading Brazilian pornochanchada as sexploitation. IN: RUETALO, R; TIERNEY, D. Latsploitation, Exploitation Cinemas, and Latin America. London: Rodutledge, 2009, p. 230-245.

. National Cinema: Introduction. In: CONDE, M.; DENNISON, S. (Eds). Paulo Emílio Salles Gomes: On Brazil and Global Cinema. University of Wales Press, 2019.

Remapping Brazilian Film Culture In The Twenty-First Century. London: Routledge, 2019.

DENNISON, S.; SHAW, L. Brazilian National Cinema. London: Routledge, 2007.

GAMO, A. C. Vozes da Boca. 2006. Tese (Doutorado em Multimeios) - Instituto de Artes, UNICAMP, Campinas, 2006

GODINHO, D.; MOURA, H. Coisas eróticas: A história jamais contada da primeira vez do cinema brasileiro. São Paulo, Panda Books, 2012.

FERREIRA, J. Cinema de Invenção. 1. ed. São Paulo: Max Limoad / Embrafilme,1986.

Cinema de Invenção. 3. ed. Rio de Janeiro: Beco do Azougue, 2016.

JOHNSON, R. Foreword. In: CONDE, M.; DENNISON, S. (Eds) Paulo Emílio Salles Gomes: On Brazil and Global Cinema. University of Wales Press, 2018.

LA GUARDIA, D. Trash culture: essays in popular criticism. Bloomington: XLibris, 2008. MATHIJS, E.; SEXTON, J. Cult Cinema: An Introdution. Chinchester: Wiley-Blackwell, 2011. 
MEDVED, M.; MEDVED, H. The Golden Turkey Awards. London: Perigee/Putnam, 1980.

MELO, V. A. Futebol e sacanagem. Blog Histórias do Esporte. 21 abr. 2016. Disponível em: <https://tinyurl.com/y68wq7er>. Acesso em: 2 dez. 2020.

MONTEIRO, T. A noiva estava de vermelho: horror e sexualidade em A mulher que inventou o amor. Revista Ícone, Recife, V. 17, n. 3, 2019, p. 365-379.

NASCIMENTO, J. C. Erotismo e relações raciais no cinema brasileiro: a pornochanchada em perspectiva histórica. 2015. (Tese de Doutorado em História) - Universidade Federal da Bahia, Salvador, 2015.

PIEDADE, L. F. R. A cultura do lixo: horror, sexo e exploração no cinema. 2002. Dissertação (Mestrado em Multimeios) - Instituto de Artes, UNICAMP, Campinas, 2002.

PINKERTON, N. Fuk Fuk à Rua do Triunfo: On Cinema da Boca do Lixo, Bolsonaro, and the Cinemateca Brasileira. Nick Pinkerton Blog, 25 nov. 2020. Disponível em: <https://nickpinkerton.substack.com/p/fuk-fuk-rua-do-triunfo>. Acesso em: 6 dez. 2020.

PRIMATI, C. Sangue, Sexo e Riso. Portal Brasileiro de Cinema - O Horror no Cinema Brasileiro. 2009. Disponível em: <https://tinyurl.com/y5ltljm3> Acesso em: 6 dez. 2020.

. O horror universal de Zé do Caixão. In: Portal Brasileiro de Cinema - Dossiê José Mojica Marins. 2007. Disponível em: <https://tinyurl.com/y2up87b5>. Acesso em: 2 dez. 2020.

RAMOS, L. Pretensões de horror, caídas no ridículo. Jornal da Tarde, São Paulo, Cinemateca Brasileira, 10 mar. 1977.

REINCHEMBACH, C.; MAZZINI, E.; ARAUJO, I. Paulo Emilio Salles Gomes: Eu só gostava de cinema estrangeiro (Entrevista). In: CAETANO, M. R. (ed). Paulo Emilio Salles Gomes: O homem que amava o cinema e que nós amávamos tanto. Brasília: $45^{\circ}$ Festival de Brasília do Cinema Brasileiro/Secretaria de Cultura do Distrito Federal, 2012, p. 74-92.

SALLES GOMES, P. E. Cinema: Trajetória no Subdesenvolvimento (1973). Rio de Janeiro: Paz e Terra, 1996.

SANCHES, R. M. O homem que calou a Boca: uma análise da obra de Raffaele Rossi. 2013. Dissertação (Mestrado em Comunicação) - Universidade Anhembi Morumbi, São Paulo, 2013.

SCONCE, J. Trashing' the academy: taste, excess, and an emerging politics of cinematic style. Screen, Londres, V. 36, 1995, p. 371-393.

TEIXEIRA, P. Seduzidas pelo Demônio, 1975. Revista Eletrônica Boca do Inferno. 01 nov. 2014. Disponível em: <https://tinyurl.com/y4w4py2k>. Acesso em: 6 dez. 2020.

TRUNK, M. Ele aprontou pra cacete. Revista Eletrônica Vice Brasil. 19 abr. 2012. Disponível em: <https://tinyurl.com/y6mrnyho>. Acesso em: 2 dez. 2020.

TRUNK, M. Chitãozinho e Xororó num filme de Raffaele Rossi. Blog Violão, Sardinha e Pão. 26 jun. 2011. Disponível em: <http://violaosardinhaepao.blogspot.com/2011/06/>. Acesso em: 6 dez. 2020. 


\section{Filmografia de Raffaele Rossi (filmes de ficção em longa-metragem):}

O HOMEM Lobo. Prod. Pinheiros Filmes. Dir. Raffaele Rossi. São Paulo. 1971. Preto e Branco, 35mm.

PEDRO Canhoto, O Vingador Erótico. Prod. E.C. Distribuidora e Importadora Cinematografica (Cassiano Esteves). Dir. Raffaele Rossi. São Paulo. 1973. Colorido, 35mm.

A GATA Devassa. Prod. E.C. Distribuidora e Importadora Cinematografica (Cassiano Esteves) Dir. Raffaele Rossi. São Paulo. 1974. Colorido, 35mm.

SEDUZIDAS pelo Demônio. Prod. E.C. Distribuidora e Importadora Cinematografica (Cassiano Esteves) Dir. Raffaele Rossi. São Paulo. 1975. Colorido, 35mm.

PURA Como um Anjo, Será... Virgem? Prod. Panther's Cine Som. Dir. Raffaele Rossi. São Paulo. 1976. Colorido, 35mm.

ROBertA, a Moderna Gueixa do Sexo. Prod. Panther's Cine Som. Dir. Raffaele Rossi. São Paulo. 1978. Colorido, 35mm.

JOÃo de Barro. Prod. Panther's Cine Som Ltda. Dir. Raffaele Rossi. São Paulo. 1979. Colorido, $35 \mathrm{~mm}$.

UMA CAMA para Sete Noivas. Prod. Panther's Cine Som Ltda. Dir. Raffaele Rossi e José Vedovato. São Paulo. 1979. Colorido, 35mm.

BONECA Cobiçada. Prod. Panther's Cine Som Ltda. Dir. Raffaele Rossi. São Paulo. 1981. Colorido, 35mm.

A CASA de Irene. Prod. Panther's Cine Som Ltda. Dir. Raffaele Rossi. São Paulo. 1981. Colorido, 35mm.

COISAS Eróticas. Prod. Empresa Cinematográfica Rossi. Dir. Raffaele Rossi e Laerte Calicchio. São Paulo. 1982. Colorido, 35mm.

COISAS Eróticas II. Prod. Empresa Cinematográfica Rossi. Dir. Raffaele Rossi e Laerte Calicchio. São Paulo. 1982. Colorido, 35mm.

DE TODAS as maneiras. Prod. Empresa Cinematográfica Rossi. Dir. Lúcio Mario e Marcelo Motta. São Paulo. 1982. Colorido, 35mm.

GEMIDOS e Sussurros. Prod. Empresa Cinematográfica Rossi. Dir. Raffaele Rossi. São Paulo. 1987. Colorido, 35mm.

Artigo recebido em 22/01/2021 e aprovado em 14/06/2021. 